time was devoted to the varied aspects of thermoluminescence (TL) dating. In a critical review of the theories of the phenomenon Professor G. J. Garlick (University of Hull) pointed out that in fundamental studies difficulties in deducing trapping parameters have arisen and that non-thermal leakage of trapped carriers has been found. This leakage, which is caused by overlap of wave functions of trapped carrier state and ground state, affects the limits of dating by this technique. The intensive investigation of TL dating, which promises so much, was shown by several contributors. A rather large array of factors, for at least some of which corrections must be made before one can reduce the errors of TL dates to small proportions, were presented, but the overall impression was that the difficulties would be overcome. Dr A. G. Wintle (University of Oxford) reported that feldspars, zircon and fluorapatite all lose some artificially induced TL from the high temperature part of the glow curve after some days storage. Fortunately, quartz and limestone do not exhibit this "fading" effect. Dr V. S. Desai (University of Oxford) showed that pottery saturated with water attenuates the escape of radon, and subsequent members of the uranium-238 decay chain, the isotopes of which are responsible for an appreciable fraction of the radiation dosage received by the pottery. Thus, changes of water content and the porosity of the pottery could modulate the dose rate received as was pointed out by $\mathrm{Dr} \mathrm{V}$. Mejdahl (University of Copenhagen); and Dr J. Huxtable with Dr M. J. Aitken (University of Oxford) demonstrated that the radioactive impurities themselves could be leached in slightly acidic conditions giving yet another potential source of error in pottery during centuries of burial.

The magnitude of the supralinearity correction routinely applied during TL dating by the fine grain method was shown by $\mathrm{S}$. J. Flemming (University of Oxford) to vary, in many instances, with the pottery's previous radiation history, and consequently affects the error in the date. Dr D. W. Zimmerman (University of Washington, St Louis) explained how these errors could be eliminated in certain special cases. He required that the inclusion in the archaeological ceramic itself was highly radioactive, as opposed to the normal case of matrix radioactivity. The zircon or apatite should have a sufficiently large internal dose rate of $\alpha$ particles to swamp any environmental $\gamma$-dosage, and this also would not be attenuated by the presence of water. Such a specimen may be used for authentication purposes even after the pottery has been X-rayed in previous analyses, a process which would prob- ably invalidate the standard TL authentication methods.

Dendrochronology was discussed at some length during one session. The method is relatively new in Britain though studied for some 70 years in the United States. Dr J. M. Fletcher (University of Oxford) presented the results of his two years' work on a series of oak trees, supplemented by timber from nearby mansions, panels from Tudor portraits and some large chests in Westminster Abbey. He has been able to construct a reference tree-ring curve back to AD 850. Similar impressive work by the palaeoecology laboratory at the Queen's University, Belfast, was described by $\mathrm{Dr}$ A. G. Smith. In four years they have assembled a series of floating tree-ring chronologies extending for about 7,000 years as attested by radiocarbon dating. This was accomplished by crosslinking oaks and pines preserved in some of the peat bogs in Ireland. It is hoped that the missing sections will soon be discovered and then a chronology rivalling that of the bristlecone pine will become available.

A spirited discussion following two contributions on methods of correcting radiocarbon dates ensued and it was postulated that two "types" of calibration curve were possible, one for explaining geophysical perturbations of atmospheric radiocarbon and another for the correction of archaeological dates. Dr H. McKerral (Scottish National Museum, Edinburgh) examined in detail corrections in the early bronze age of Britain and concluded that corrected dates were much later than expected on historical grounds. A statistical investigation by Professor C. Renfrew (University of Southampton) and Dr R. M. Clark (University of Sheffield) of bristlecone pine calibrated and historically dated Egyptian samples indicated that the errors of the radiocarbon dates had been underestimated or that the assigned calendar dates of some of the samples were in error, or both. Calibration curves fitted by computer indicated, however, that the Egyptian and the bristlecone pine data are compatible within the relevant time period. The fear initiated among some archaeologists by a "red herring" in a recent review article, that the bristlecone pine calibration data might be distorted by as much as 1.5 per cent by carbon-14 produced in situ in trees growing at high altitude by the action of cosmic ray neutrons with nitrogen fixed in the cellular structure of the wood, was allayed by Drs D. Harkness (Scottish Research Reactor Centre, East Kilbride) and R. Burleigh (British Museum) who reconsidered the theoretical predictions. They suggested that the amount of radiocarbon thus produced is below the limit of measurement, and so could not affect the calibration curve.

\title{
A New Protein Controlling Cell Division
}

IN Escherichia coli the completion of DNA replication is a prerequisite for cell division. It is known that protein synthesis is essential for cell division and, to date, two distinct periods of protein synthesis have been described, the first being required for the initiation of replication, the second taking place concurrently with replication. In Nature New Biology next Wednesday (May 23), Jones and Donachie describe a third period of RNA and protein synthesis which occurs at or subsequent to completion of DNA replication.

Jones and Donachie used a strain of $E$. coli which is able to resume RNA synthesis after treatment with rifampicin and removal of the antibiotic from the medium. They pretreated their cells in such a way that they became synchronized with respect to a single round of DNA replication and a single subsequent wave of division. Readdition of thymine after pretreatment led to a synchronous reinitiation of chromosome replication within $10 \mathrm{~min}$. The replication was complete by $40 \mathrm{~min}$ and was followed $5 \mathrm{~min}$ later by cell division. Inhibition of completion of the first round of chromosome replication prevented cell division.
Addition of rifampicin up to $35 \mathrm{~min}$ after administration of thymine prevented most division but addition at $45 \mathrm{~min}$ had no effect on division. Addition of chloramphenicol at any time up to $40 \mathrm{~min}$ after thymine prevented all cell division. Later addition of chloramphenicol had no effect. Thus RNA and protein synthesis are required 5-10 min before division. RNA synthesis is not required at an earlier time, because if rifampicin is added at the same time as thymidine and subsequently removed (before the $5-10 \mathrm{~min}$ prior to division), the timing of division is unaffected. Furthermore, synthesis of this specific RNA and protein required for division can take place only after the replication of a late segment of the chromosome. Once fermentation has occurred, RNA and protein synthesis required for division can take place even after a 30 min delay.

These experiments therefore demonstrate the existence of a "termination protein" the synthesis of which is signalled by the completion of DNA replication and the function of which is presumably to act to prevent cell division before completion of chromosome duplication. 